\title{
Task force urges medical school networking
}

Published at www.cmaj.ca on June 3

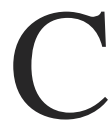

anada's 17 medical schools should evolve into academic health sciences networks, whose operations are more closely integrated with all levels of government, local health authorities, health facilities and other organizations affiliated with the health enterprise, according to a blue-ribbon task force.

"Applied health sciences research is happening in community hospitals and family practices," says Glenn Brimacombe, president of the Association of Canadian Academic Healthcare Organizations and chair of the steering committee which brought together representatives from different universities, health associations and research groups for the task force. "More of the research has expanded outside of the walls of the health sciences centre. It's pushed out into the community and this framework will capture that knowledge and bring everyone together."

The National Task Force on the Future of Canada's Academic Health Sciences Centres' final report, Three Missions, One Future ... Optimizing the Performance of Canada's Academic Health Sciences Centres, released May 31, calls for more integration between medical schools and regional bodies, while maintaining "worldclass" standards of health care, training and research.

Dr. Jean Rouleau, dean of medicine at the Université de Montréal in Quebec and cochair on the task force, says the progression to health networks has already begun.

"The world is changing, the environment in which we're working is changing, and it's one favouring interaction between various players," explains Rouleau. "But, the evolution is very spotty across the country. There is some progress made, but we still have a long way to go."

Rouleau says that the report's recommendations emphasize best practices for

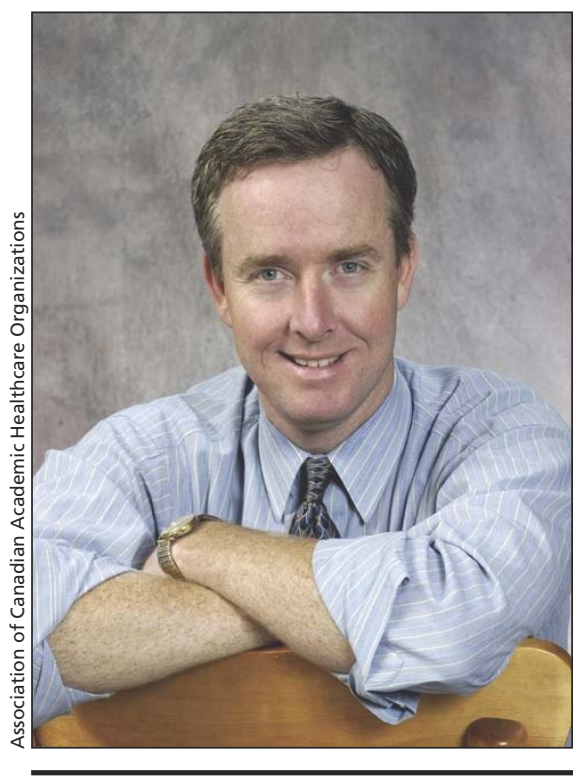

Glenn Brimacombe, president of the Association of Canadian Academic Healthcare Organizations, says medical schools need to become more integrated with their communities to "close the gap from new knowledge to practice."

the evolution. "Across the country there are some elements that have been developed, but in every part of the country there are things that can be done to make things significantly better."

One improvement, proposed in the report, is a more integrated relationship with federal and provincial or territorial governments to generate more monies for medical schools (http: //ahsc-ntf.org/docs/AHSCs/NTF\%20 Report/Final\%20Report/05.30-NTF-E N-FINAL.pdf).

According to the task force, the additional costs of increasing enrolment in medical schools and more complex treatments for an aging population are creating a funding shortfall for academic health sciences centres. The report highlights "competing agendas, conflicting policies and fragmented priorities" as barriers to increased government funding.

Brimacombe says a more integrated approach would provide "coordinated policy discussions" and, hopefully, improved funding opportunities.

Academic health sciences centres can also work on better articulating how the goals of the organization coincide with the goals of the government, says Dr. Jim Rourke, dean of medicine at Memorial University in St. John's, Newfoundland and Labrador. He points out that medical innovation can translate into good economic sense for the country.

"It's important not to just do what we need to today, but to do what we must to get to where we need to be tomorrow," says Rourke, who also served on the task force. "Health care is expensive. This is about trying to invest now in research that will have longterm outcomes that will improve our situation across Canada."

Rourke adds that bolstered funding "should lead to increased health care research and commercialization opportunities. This will help the research, but also drive our economy."

The task force is also looking for federal and provincial governments, as well as members of the medical community, to change their perception of academic health sciences centres: from localized teaching hospitals to locations of highly specialized care and internationally significant research.

"All [of the health centres] have a role regionally, provincially and in some cases nationally and internationally," says Rouleau, "and all of them have a particular expertise. For some there will be broader significance than others." As an example, Rouleau cites the Hospital for Sick Children in Toronto, Ontario, which "has an international reputation, but it also has a role to play in the optimization of care in the Greater Toronto Area as well."

The task force recommendations appeared to be well received within the nation's medical schools, many of whom feel they are already in the process of becoming academic health sciences networks. 
Dr. Tom Feasby, dean of medicine at the University of Calgary in Alberta, says the report has captured the spirit of change now in evidence at centres across the country. His institution is now working with the University of Alberta in Edmonton to create a network where the two schools can work together on research important to the health of people in the region.

"I think there are huge benefits to this approach," says Feasby. "Patients can benefit from the most up-to-date research, and universities can tailor the education process to create the kinds of health care professionals that the community needs. It's better than working in isolation."
In London, Ontario, Dr. Carol Herbert says the Schulich School of Medicine \& Dentistry has been progressing toward this network model for several years. The University of Western Ontario dean of medicine adds that there is now "a multiplicity of players" taking part in a collaborative system, instead of a hierarchy with the medical school at the top.

"We decided some time ago that it was important to train people outside of urban centres," says Herbert, describing one example of the shift away from a traditional model of an academic health sciences centre. "Learners should be familiar with rural, urban and regional care, so they are able to work in a variety of places."

Brimacombe agrees that academic health sciences centres need to look beyond traditional research structures and hopefully gain additional insight into what needs to be taught at the university. "We want to close the gap from new knowledge to practice."

The task force hopes that by creating this more integrated process of education, research and patient care, they can speed up the transition from "the classroom, to the laboratory, to the bedside." - Elyse Skura, Ottawa, Ont.

DOI:10.1503/cmaj.109-3276 